\title{
Modeling and Prediction of New Energy Use
}

\author{
Ruiming Yang*, Leiyuan Li \\ Department of Communications and Information Engineering, Century College, Beijing University of Posts and Telecommunications, \\ Beijigng, China
}

Email address:

18811516615@163.com (Ruiming Yang), lileiyuan1985@163.com (Leiyuan Li)

${ }^{*}$ Corresponding author

\section{To cite this article:}

Ruiming Yang, Leiyuan Li. Modeling and Prediction of New Energy Use. Journal of Energy and Natural Resources.

Vol. 8, No. 2, 2019, pp. 87-97. doi: 10.11648/j.jenr.20190802.16

Received: April 21, 2019; Accepted: May 22, 2019; Published: June 15, 2019

\begin{abstract}
This paper looks into clean energy consumption in the four states of California (CA), Arizona (AZ), New Mexico (NM) and Texas (TX) by analyzing and comparing the methods of energy consumption, the similarity and difference of their energy composition and the causes for it, and finding out the state with the optimal ways of energy consumption, and based on it, predicts the future energy composition of these states and proposes a target for interstate energy convention. And through multiple regression analysis, and the corresponding indicators of the methods of energy consumption in these states, we compare the ways of new energy consumption in these states, and analyze the difference from the perspective of industries and geographies in these states, which prepares necessary reference for the following modeling. After some basic analysis of the data, we establish a multi-attribute decision making to find a state with optimal composition of energies through the five indicators of energy composition, volume of clean energy consumption etc; and based on the analysis, we find the different characteristics of energy consumption in these states. Then we set up a GM $(1,1)$ model to make prediction based on the data of energy consumption of the near 20 years and project energy consumption of the four states in 2025 and 2050. By means of multi-attribute decision making, we find out the state with optimal energy composition, and propose a target of the energy convention based on a two-year clean energy consumption in this state. After analyzing the difference of energy consumption methods in these four states, and in order to coordinate and integrate energy production and consumption in these states, we propose the 6 suggestions for action. In addition to the multiple regression analysis, multi-attribute decision making for the analysis of the energy consumption in these four states, principal component analysis also plays an important role. This method helps to find the significance of different ways of energy consumption, figure out the current and future energy consumption in these four states, and the state with optimal energy consumption method. Finally, by means of comparing with different models, we have nearly the same conclusion: CA is a state with optimal energy combination and has best practice for future development. There in projecting the 2025 and 2050 energy consumption, we can use CA as a reference state and set such as the target for energy convention between these four states.
\end{abstract}

Keywords: Multiple Regression Analysis, Multi-attribute Decision Making, Principal Component Analysis

\section{Introduction}

With the rapid development of the world economy, production and use of energy play an increasingly important role in the economy. In any country, the production and rational use of energy are all very important, such as the 1970 interstate energy contract in the western United States. To promote the development of clean and renewable energy production today, governors from four states (CA, AZ, NM, Texas) are demanding data analysis to develop a comprehensive package of intercontinental energy contracts $[1]$.

In the long run, the production and use of energy has always been a major part of the economy. The lack of energy or waste will bring problems to the country and nature. For this reason, the rational use of energy has drawn much attention and promotion. For example, the United States Western Interstate Energy Contract (WIEC). 


\section{Method}

There are now four continents need to establish an energy contract, the preparatory work before the establishment of the contract may need to solve the following problems:

1. Create energy profiles and configurations for the four states from the data provided.

2. Development Model Describes how to use renewable clean energy in the historical evolution of the four continents and to make the model as simple as possible.

3. Determine which state has the 'best' use of clean energy and explain the criteria.

4. Based on historical evolution between states, speculate on the energy profiles of each state in 2025 and 2050 without policy adjustments.

5. Set the goals of the Interstate Energy Contract based on the previous analysis.

6. Discuss at least three actions that need to be taken to achieve a compact energy goal.

7. Prepare a one-page summary memorandum outlining the status of 2009 to project changes in energy use without policy changes, and propose targets for adoption of energy covenants.

Before this issue, there are many research papers on the rational collocation and exploitation of energy, and most of the research literature classes are divided into two categories: micro and macro.

Here the official gives a large number of data cases, then we analyzed the meaning of most of the data, excluding some of the analysis of useless data, and differentiate data classification and summary. We will use it in the following model.2009-2050 economic and energy development of these four state will not be influenced by any peculiar factor. Data are authentic and from sound sources. Leaving out some peculiar statistic will not have any consequence on the result of analysis.

Table 1. Notations

\begin{tabular}{ll}
\hline Symbols & Definition \\
\hline$A_{i j}$ & Property value \\
$R_{i j}$ & Normalized attribute value \\
$C$ & Posterior difference ratio \\
$S_{1}$ & Raw data variance \\
$S_{2}$ & Residual variance 2 \\
\hline
\end{tabular}

\subsection{Data Collection}

There are large quantities of data concerning energy consumption in these four states, and some are actually interconnected [2]. We choose some data with representative characteristics for the analysis, but it still leaves us with nearly 30 types of data. Nuclear, fuel ethanol, biomass, geothermal energy, solar and natural gas are generally considered clean and renewable energies [3]. We are going to analyze their consumption, import, prices and their consumption in each state. Based on the differences from the comparison and contrast, we have a general picture of energy consumption in these four states in the past 50 year, the percentage of the clean energy, then we have the energy consumption of the last 10 years and the trend of future energy consumption [4].

Clean and renewable energies have been discovered and used for long. In some states, because of their natural conditions, historical reasons, or the industrial development, the research into and use of clean and renewable energy started earlier than in other states. Therefore we have found obvious differences in energy consumption in these states.

TX has larger MMTCB, CA and MM are moderate, AZ experiences a low level.

As for MUETB, CA started earlier; CA, TX and AZ got a leap forward in the 1980s and 1990s. And up to now, all these three states have similar amount of nuclear power, among them TX generated the most. MM has no nuclear power up to now.

In terms of GETCB, the amount consumed in CA is much larger any other state. TX, NM, and AZ have relatively low level of consumption.

As to SOTXB, CA also consumes more than the other states, TX, MM, and AZ have low levels of consumption.

In the last two decades, natural gas consumption in $\mathrm{AZ}$ constitutes $57.66 \%$ of its clean energy, and nuclear power takes $37.33 \%$. In CA, natural gas takes around $75.88 \%$, and nuclear power $11.4 \%$. In MM, natural gas takes $95.08 \%$, and nuclear power is $0.00 \%$. In TX, natural gas takes $89.69 \%$, and nuclear power $7.66 \%$ [5].

In CA, NM, TX, CITXB is comparatively large, among them, TX consumes twice of that of CA. CA and MM consume similar amount, and $\mathrm{AZ}$ stays at the bottom. The consumption of PCTCB increased in CA and TX, and started to decrease 5 years ago. AZ and MM enjoy low level of PCTCB. In TX, KSTCB has been much more than other states, increased sharply in 1970s and 1980s, and dropped dramatically after 1980s [6]. From this analysis, we find that TX spends quite a lot in non-renewable energy, CA stays at lower middle level, AZ and MM have low level PCTCB.

After processing the data, we have four indicators, namely the ratio of clean energy consumption to their total energy consumption of the last 20 years, the average price of exported electricity, the volume of clean energy, and the total production of "coal, petroleum, and kerosene" in the last 20 years. As to the ratio of clean energy consumption to total energy consumption of the last 20 years, AZ has the largest figure, $83.31 \%$, TX the smallest, $63.56 \%$. As for the average prices of exported electricity, CA and TX are the highest, $10.832, \mathrm{MM}$ is the lowest, 4.007. In the category of total production from clean energy, CA has the largest decisive factor, 14598811, and NM the smallest, 49868. And TX enjoys the largest total production of "coal, petroleum, and kerosene" in the last 20 years, 5225672.9, while NM is the smallest, 107403.06 . 


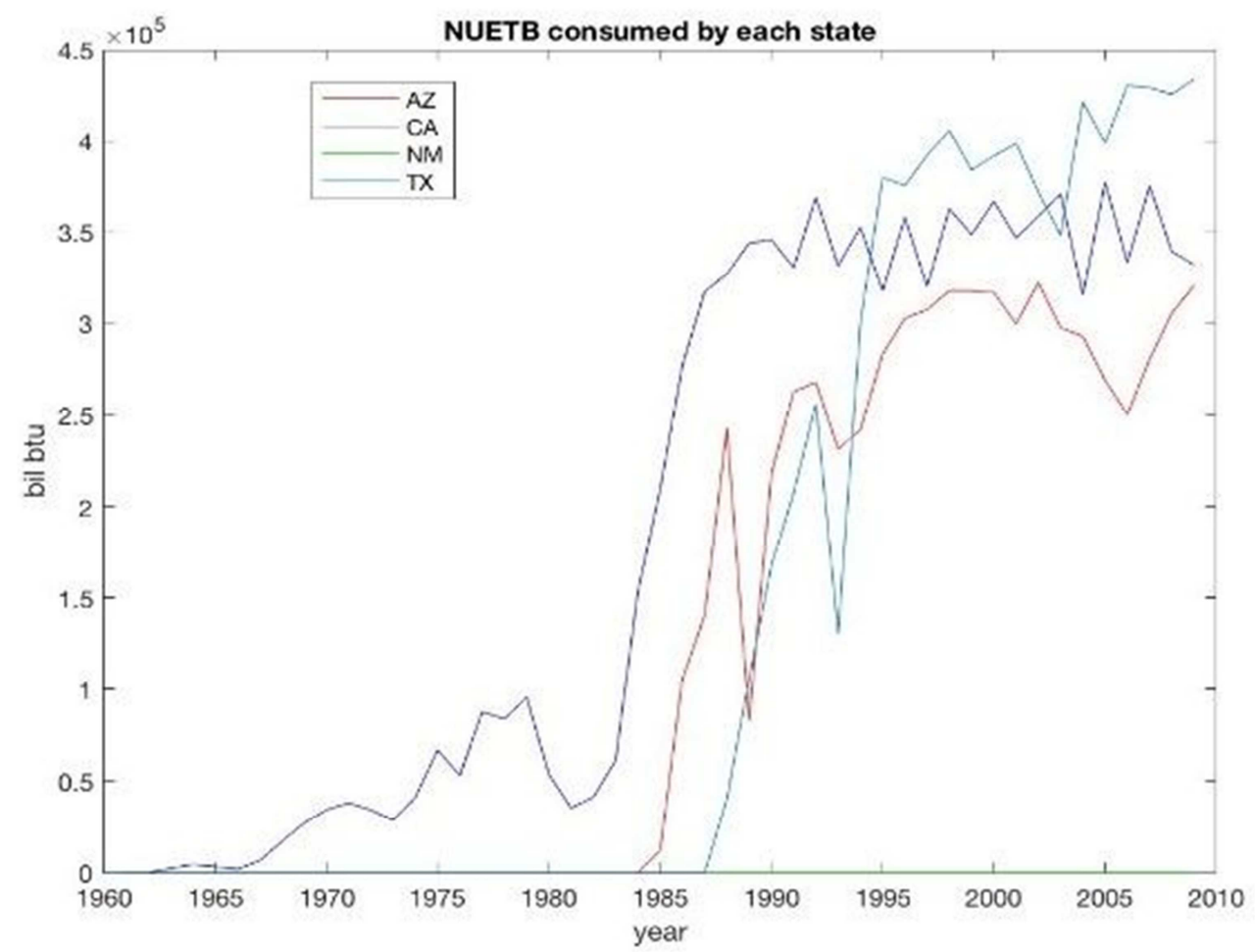

Figure 1. NUETB.

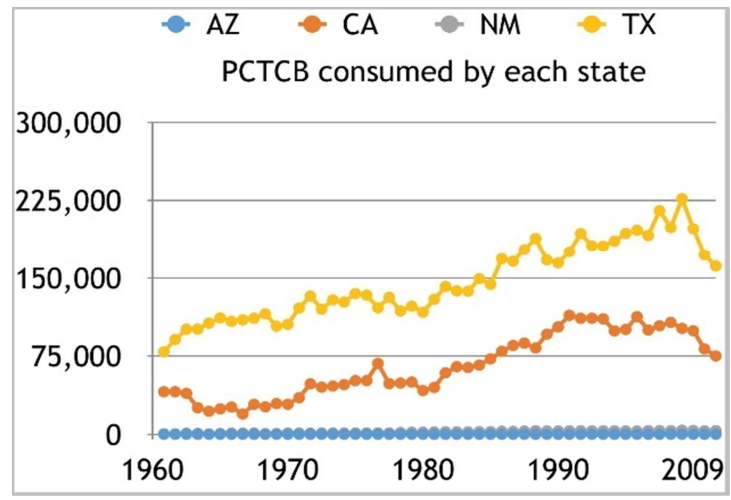

Figure 2. $P C T C B$.

In the four states, energy consumed in TX is mainly from non-renewable energy, and CA mainly renewable energy, AZ and NM enjoy low level energy consumption.

According to the above analysis, TX enjoys rich natural resources, and its energy mainly depends on coal, kerosene and other natural resources; but in recent years, its consumption of clean and renewable energy increased a lot, and the consumption of non-renewable energy has started to decrease, still at a high level though. CA started earlier than other states in the use of renewable energy, and stays at a mid-level in the consumption of non-renewable energy. And as years go by, its consumption of renewable energy increased constantly and that of non-renewable energy kept decreasing. In energy consumption, $\mathrm{AZ}$ and $\mathrm{NM}$ stay at a low level in comparison with CA and NM. There is little difference of consumption of the two types of energies. They actually import some energy.

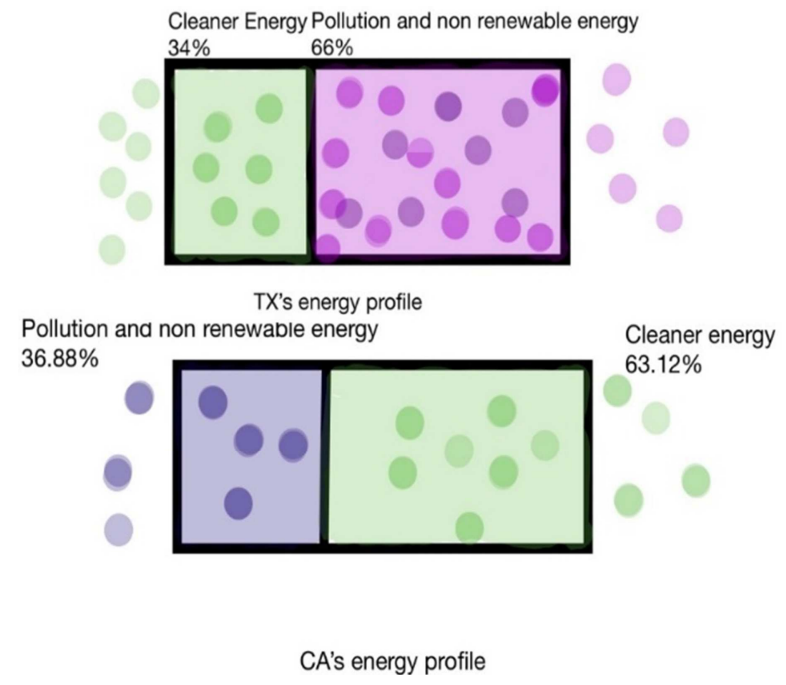

Figure 3. Energy profiles in $T X$ and $C A$.

\subsubsection{Model Building and Solving Part 1}

Regression Analysis Definition: Regression analysis is a method of statistical analysis of data, the purpose is to understand whether two or more variables related to the relevant direction and intensity, and to establish mathematical models in order to observe the specific variables to predict the researchers interested variable. Regression analysis thinking:

The basic idea of regression analysis is that although there is no strict and deterministic functional relationship between independent and dependent variables, one can try to find the mathematical expression that best represents the relationship between them [7].

For the first part of the B problem, we investigated the 
history, environment, industry, humanities and other factors among the states, and collected 50 years of energy exports such as four states in the data source [8], for all types of non-renewable energy consumption, various types of typical clean energy consumption, various types of non-clean energy consumption, such as more than 30 kinds of data types were analyzed by multiple regression analysis, the results of the analysis found four states of the economy and all kinds of energy distribution and consumption relationship.

According to the relevant data, we think that CA has the best prospect of developing clean energy. In addition to the above data, we speculate that $\mathrm{CA}$ has the most promising prospects for clean energy development because all the technical and economic indicators concerning CA calendar year provided by the National Bureau of Statistics are among the highest in the four states. [9] Geographically, CA, on the one hand, relies on the Rocky Mountains and on the other hand, it is not conducive to continuous energy input due to the geographical conditions of the Pacific Ocean. In order to meet the coordinated development of various industries developed in the CA state and the relatively barren non-clean energy conditions, CA has formed a set Good clean energy use programs and regulations. According to the National Bureau of Statistics on the laws and regulations of the U. S. states, CA has the largest number of clean energy incentives laws in the four states, and from the government financial reports of the four states, The most funds invested in the exploitation and utilization of clean energy are in these four states, so CA also has the best industrial base for developing clean energy.

Multi-attribute decision-making is an important part of modern decision-making science. Its theories and methods have been widely used in many fields such as engineering design, economy, management and military, such as investment decision, project evaluation, maintenance service, weapon system performance Assessment, site selection, tendering and bidding, ranking of industrial development and comprehensive evaluation of economic benefits, etc. The essence of multi-attribute decision-making is to sort or select a.

Then determine the weight between the various levels of factors, if only to give qualitative results, often not be accepted, Indians Santy et al proposed: consistent matrix method, namely:

1. Do not put all the factors together, but rather compare each other.

2. The relative scale of the matter to minimize the nature of the various factors that make the comparison more difficult and improve accuracy. [10]

Pairwise comparison matrices are comparisons of the relative importance of all the factors in this layer to one of the factors above. The element Aij of the paired comparison matrix is given as a SANTY 1-9 scale.

Table 2. A SANTY 1-9 scale.

\begin{tabular}{ll}
\hline Scaling & Meaning \\
\hline 1 & It is equally important that two factors are compared \\
3 & One factor is slightly more important than the other \\
5 & One factor is obviously more important than another \\
7 & One factor is more important than another \\
9 & One factor is more important than another \\
$2,4,6,8$ & Median of the above adjudication \\
reciprocal & Judgment of factor $\mathrm{i}$ compared with $\mathrm{j}$ aij, Judgment of factor $\mathrm{j}$ compared with $\mathrm{i}$ aji $=1 /$ aij \\
\hline
\end{tabular}

The data we selected for the evaluation indicators are all good.

Gray Forecast Model is a prediction method for making mathematical models and making predictions through a small amount of incomplete information. The gray system theory was proposed and developed by Professor Deng Ju-long of Hua Zhong University of Science and Technology in 1982.

The features of grey system: Grey mathematics can be applied to quantize the uncertain variablesThe certain information can be applied to identify the dynamics of the system. The theory of grey system can be plied to lean information system.

The original data in a data column is processed based on certain requirements, and we call this data processing as generation. Commonly-used gray system generation methods are: cumulative generation, cumulative generation, average generation, level generation, etc. Here we use the cumulative generation.

The accumulative generation is the new data and sequence yielded by the accumulation of individual data of different points of time in different sequences. The sequence before generation is referred as original sequence, and the sequence after generation is referred as generated sequence. The accumulative generation is the way that transform the grey system from grey to white, and it plays an very important role in the theory of grey system. We can observe the dynamics of grey level accumulating process by accumulative generation, which can make explicit the accumulative features or law underlain in the chaotic raw data.

The formula is:

$$
x^{(1)}(i)=\left\{\sum_{j=1}^{i} x^{(0)}(j) \mid i=1,2, L, N\right\}
$$

The data columns in the above expression are referred to as the first order accumulated generating operation of raw data columns, for short, as the first order accumulated generating operation.

Grey system is the differential equation of discrete series, $\operatorname{GM}(1,1)$ is the model of first-order differential equation, its expression as: $\frac{d x}{d t}+a x=u G M(1,1)$.

The discrete form and prediction formula are as follows:

$$
\Delta^{(1)}\left(x^{(1)}(k+1)\right)+a(x(k+1))=u
$$




$$
\hat{x}^{(1)}(k+1)=\left[x^{(1)}-\frac{\widehat{u}}{\hat{a}}\right] e^{-\hat{a} k}+\frac{\widehat{u}}{\hat{a}} X^{(0)}
$$

After we have selected the model, we should test it to judge if it is reasonable, then the model can be applied to forecasting. There are three methods to accuracy test of grey model: relative error test, relevance test and posterior-variance-test. Here we will adopt the posterior-variance-test: We assume that we have yielded $\hat{X}^{(1)}$ based on model creating method of $G M(1,1)$, and conduct a first order subtract consecutively to $\hat{X}^{(1)}$, then we have residual calculation, yield $e(k)=$ $x^{(0)}(k)-\hat{X}^{(0)}(k), k=1,2, L, n$.

The variances of original sequence $X^{(0)}$ and residual sequence:

Separately, we have $S_{1}^{2}$ 和 $S_{2}^{2}$,

$$
\begin{gathered}
S_{1}^{2}=\frac{1}{n} \sum_{k=1}^{n}\left[x^{(0)}-\bar{x}\right]^{2} S_{2}^{2}=\frac{1}{n} \sum_{k=1}^{n}[e(k)-\bar{e}]^{2} \\
\text { where, } \bar{x}=\frac{1}{n} \sum_{k=1}^{n} x^{(0)}(k)=\frac{1}{n} \sum_{k=1}^{n} e(k)
\end{gathered}
$$

We calculate the ratio of posterior-variance, and yield:

$$
C=S_{2} / S_{1}
$$

Table 3. Accuracy Test Grade.

\begin{tabular}{ll}
\hline Model accuracy level & Mean square error ratio C \\
\hline Level 1 (good) & $\mathrm{C}<=0.35$ \\
Level 2 (qualified) & $0.35<\mathrm{C}<=0.5$ \\
Level 3 (barely) & $0.5<\mathrm{C}<=0.65$ \\
Level 4 (failed) & $0.65<\mathrm{C}$ \\
\hline
\end{tabular}

We think that there are many factors that will impact the use of energy, including some historical factors. And among these factors, the power of some of them will be weaken over time, and the others will be stronger. So it will be resulted in more accurate conclusions to forecast the data of energy usage of years later with $\operatorname{GM}(1,1)$.

We expect to forecast the data of energy usage of 4states in U. S. in 2025 and 2050.

Based on the data of energy usage in the 4 states in U. S. during recent 20 years, we will forecast the relevant energy-using data in 2025 . And then we will forecast the data of energy usage in 2025 based on the ever forecasting data in

\begin{tabular}{|c|c|c|c|c|c|}
\hline $\begin{array}{l}\text { State } \\
2025\end{array}$ & $\begin{array}{l}\text { Nearly } 20 \text { years of total clean energy } \\
\text { consumption as a percentage of total } \\
\text { energy consumption }\end{array}$ & $\begin{array}{l}\text { The average price of } \\
\text { exported electricity }\end{array}$ & $\begin{array}{l}\text { The total energy } \\
\text { generated by } \\
\text { clean energy }\end{array}$ & $\begin{array}{l}\text { Regression equation in each } \\
\text { state the coefficient of } \\
\text { pollution energy share }\end{array}$ & $\begin{array}{l}\text { Total output of } \\
\text { coal tar oil in }\end{array}$ \\
\hline $\mathrm{AZ}$ & $83.531 \%$ & 7.264211 & 320622.2615 & 5.785 & 32588.64 \\
\hline $\mathrm{CA}$ & $83.8511 \%$ & 6.232011 & 352149.5800 & 5.189 & 385219.32 \\
\hline NM & $82.44 \%$ & 3.542083 & 263424.196 & 22.491 & 157453.07 \\
\hline TX & $70.21 \%$ & 11.61202 & 322670.645 & 38.781 & 7125422.1 \\
\hline
\end{tabular}
2009 and 2025 (for the forecasting procedure and data, see the attachment 4).

Table 4. The prediction of energy usage in 2025 .

Posterior-variance: 0.64 , the accuracy of forecasting data is average.

General situation: In 2005-2025, CA will have the highest proportion of the consumption of clean energy to the total energy consumption while TX will have the lowest one. In terms of the average price of export electricity, NM will rank as the lowest state and TX will have the highest average price. CA will enjoy the largest amount of energy produced by clean energy while NM will have the lowest one when it comes to the gross energy generated by clean energy. In addition, with respect to the cumulative sum of the coal tar production in 2005-2025, TX will be the largest producer of coal tar and NM will stay at the bottom.

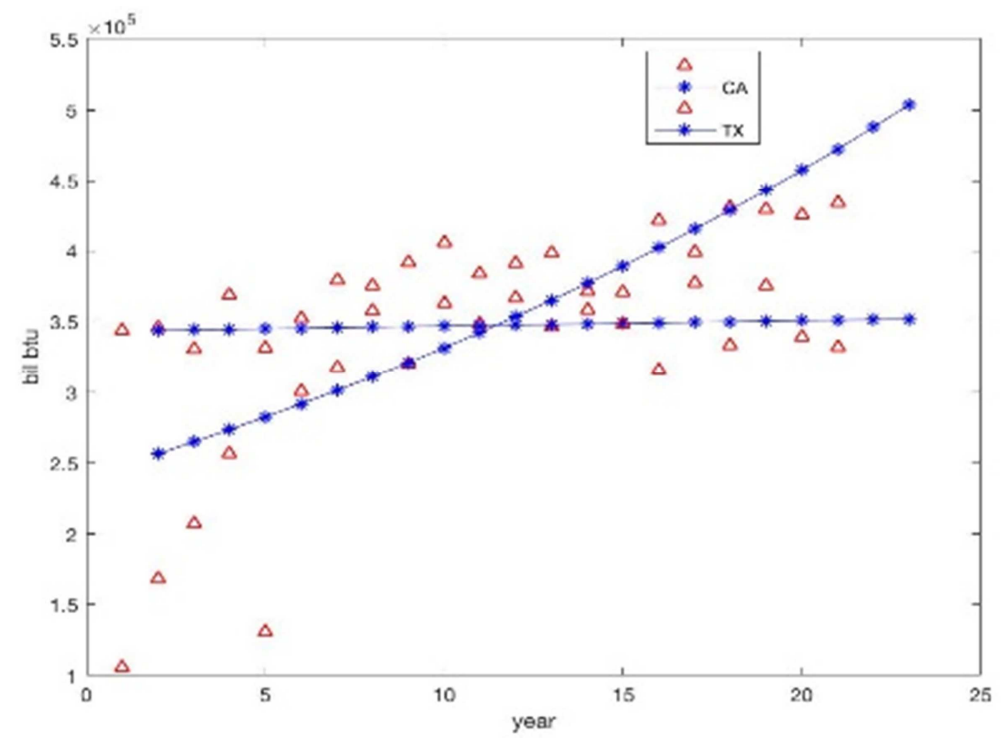

Figure 4. NUETB. 
Table 5. The prediction of energy usage in 2050.

\begin{tabular}{|c|c|c|c|c|c|}
\hline State 2025 & $\begin{array}{l}\text { Nearly } 20 \text { years of total clean energy } \\
\text { consumption as a percentage of total } \\
\text { energy consumption }\end{array}$ & $\begin{array}{l}\text { The average } \\
\text { price of exported } \\
\text { electricity }\end{array}$ & $\begin{array}{l}\text { The total energy } \\
\text { generated by clean } \\
\text { energy }\end{array}$ & $\begin{array}{l}\text { Regression equation in } \\
\text { each state the coefficient } \\
\text { of pollution energy share }\end{array}$ & $\begin{array}{l}\text { Total output of } \\
\text { coal tar oil in }\end{array}$ \\
\hline $\mathrm{AZ}$ & $81.288 \%$ & 7.1761225 & 380722.9615 & 6.785 & 3556188.61 \\
\hline $\mathrm{CA}$ & $89.3511 \%$ & 6.832115 & 40849.3800 & 5.386 & 365269.35 \\
\hline NM & $82.62 \%$ & 6.542283 & 284204.796 & 23.491 & 187403.01 \\
\hline $\mathrm{TX}$ & $70.12 \%$ & 14.65209 & 399670.695 & 32.781 & 6322622.7 \\
\hline
\end{tabular}

Posterior-variance: 0.64 , the accuracy of forecasting data is average.

General situation: In 2030-2050, among these four states CA will keep the highest proportion of the consumption of clean energy to the total energy consumption and TX will remain at the bottom. Besides, TX will have the highest average price of export electricity, the most cumulative sum of the coal tar production in 2030-2050, as well as the highest sum of the coefficients of non-renewable energy. NM will have the lowest average price of export electricity and the least amount of energy generated by clean energy. [11]

\subsubsection{Model Building and Solving Part 2}

Based on the comparison between four states, the evaluation criteria put forward in Problem $\mathrm{C}$ and the prediction of their energy structure in 2025 and 2050 in Problem D, we evaluate their general situation of clean energy in 2025 and 2050 again and try to find out the best one whose values will be chosen as the goals in 2025 and 2050 .

The model is expected to get the following indexes of four states in 2025 and 2050.

1. The proportion of the consumption of clean energy to the total energy consumption in the nearly 20 years.

2. The average price of export electricity.

3 . The gross energy generated by clean energy.

4. The sum of the coefficients of renewable energy in the regression equations of four states.

5. The cumulative sum of the coal tar production in the nearly 20 years.

Based on the indexes of four states in 2025 and 2050 in the previous section, the normalization processing has been conducted.

Table 6. The index of normalization processing in 2025.

\begin{tabular}{lllll}
\hline State 2025 & $\begin{array}{l}\text { Nearly 20 years of total clean energy } \\
\text { consumption as a percentage of total } \\
\text { energy consumption }\end{array}$ & $\begin{array}{l}\text { The average price } \\
\text { of exported } \\
\text { electricity }\end{array}$ & $\begin{array}{l}\text { The total energy } \\
\text { generated by } \\
\text { clean energy }\end{array}$ & $\begin{array}{l}\text { Regression equation in each } \\
\text { state the coefficient of } \\
\text { pollution energy share }\end{array}$ \\
\hline AZ & 1 & 0.7091 & 0.8079 & 0.5021 \\
CA & 0.8864 & 1.0000 & 1 & 1 \\
NM & 0.8959 & 0.5682 & 0.0134 & 0.0368 \\
TX & 0.8029 & 1 & 0.5808 & 0.1566 \\
\hline
\end{tabular}

Through the Part $\mathrm{C}$ ask weight calculation weighted arithmetic average operator to calculate the score of four states:

$[\mathrm{AZ}, \mathrm{CA}, \mathrm{NM}, \mathrm{TX}]=[0.313,0.871,0.521,0.853]$

Table 7. The index of normalization processing in 2050.

\begin{tabular}{|c|c|c|c|c|c|}
\hline State 2025 & $\begin{array}{l}\text { Nearly } 20 \text { years of total clean energy } \\
\text { consumption as a percentage of total } \\
\text { energy consumption }\end{array}$ & $\begin{array}{l}\text { The average } \\
\text { price of exported } \\
\text { electricity }\end{array}$ & $\begin{array}{l}\text { The total energy } \\
\text { generated by clean } \\
\text { energy }\end{array}$ & $\begin{array}{l}\text { Regression equation in } \\
\text { each state the coefficient } \\
\text { of pollution energy share }\end{array}$ & $\begin{array}{l}\text { Total output of } \\
\text { coal tar oil in }\end{array}$ \\
\hline $\mathrm{AZ}$ & 1 & 0.6091 & 0.7882 & 0.6021 & 0.2004 \\
\hline $\mathrm{CA}$ & 0.9663 & 0.9782 & 1 & 1 & 0.7021 \\
\hline NM & 0.8758 & 0.4766 & 0.0134 & 0.0466 & 0.3050 \\
\hline TX & 0.7929 & 1 & 0.7108 & 0.3843 & 1 \\
\hline
\end{tabular}

Calculated by weighted average arithmetic operator four states scored:

$$
[\mathrm{AZ}, \mathrm{CA}, \mathrm{NM}, \mathrm{TX}]=[0.423,0.902,0.582,0.791]
$$

The taxes on the industries using renewable energy sources should be reduced and fiscal subsidies be given to the companies that produce renewable energy sources by the state governments;

The taxes on the industries that do not use clean energy should be increased by the state governments so as to facilitate the transformation of the related industries which heavily rely on non-regeneration energy. Meanwhile, fiscal subsidies should be accordingly provided to the transformed industries.

As for scientific researches, the related research projects should be carried out by the state governments to explore the patterns of the utility and production of renewable energy sources that are more efficient and economical.

As for plans, the state governments are supposed to lay down the suitable utility patterns of renewable energy sources according to their own situations, such as resources and geography.

As for laws, more laws and regulations that are benefit to 
the healthy development of renewable energy sources should be enacted by the state governments.

As for macroeconomic regulatory, the state governments should give energetic support to new energy, such as biomass energy which can be used to produce fuel gas after gasification and fuel alcohol; the major efforts should be devoted to developing clean energy for yielding electricity, including unclear energy, wind energy and Hydraulic; moreover, the government ought to regulate the export and import of energy, and reduce the usage of energy that can generate pollution, such as coal and petroleum whose price is expected to increase; in addition, it's necessary to advocate clean energy and cut down the price of some related products.

\subsection{Simulation Result}

Through analyzing the data types in data sources and the economic impact of different energy distributions on different states, we hope to find the important influencing factors that affect the energy allocation in each state, and analyze the factors affecting the allocation of resources in each state through the factors of climate, environment and industry in each state.

Through the data collection, we sort out the various types of state clean energy consumption, various types of non-clean energy consumption and imports and other data, and multiple linear regression, here is our regression data:

BMTCB EMTCB GETCB HYTCB NNTCB NUETB PLICB SOTXB ARTCB AVTXB CLTXB JFTCB KSTCB LGTCB PCTCB WWTCB ELEXB RETCB

Among them, taking RETCB as the dependent variable in the regression equation and other variables as the independent variables, the equations can be used to describe the differences in the way which energy is used by each state.

The model expects to judge the state with the best energy usage profile by various evaluation criteria.

Because of the variety of data types in the data source, we extracted five indicators of greater influence for evaluation, in descending order of importance:

1. Nearly 20 years of total clean energy consumption of all energy consumption than the ratio.

2. The average price of export electricity.

3. The total energy generated by clean energy.

4. Regression equation in each state, the coefficient of clean energy share.

5. Coal tar energy output cumulative sum of nearly 20 years.

We constructed the decision matrix through data processing.

Table 8. The decision matrix before normalization.

\begin{tabular}{llllll}
\hline State 2025 & $\begin{array}{l}\text { Nearly 20 years of total clean energy } \\
\text { consumption as a percentage of total } \\
\text { energy consumption }\end{array}$ & $\begin{array}{l}\text { The average } \\
\text { price of exported } \\
\text { electricity }\end{array}$ & $\begin{array}{l}\text { The total energy } \\
\text { generated by clean } \\
\text { energy }\end{array}$ & $\begin{array}{l}\text { Regression equation in } \\
\text { each state the coefficient } \\
\text { of pollution energy share }\end{array}$ & $\begin{array}{l}\text { Total output of } \\
\text { coal tar oil in }\end{array}$ \\
\hline AZ & 1 & 0.8091 & 0.7079 & 0.6021 & 0.0566 \\
CA & 0.8664 & 1.0000 & 1 & 1 & 0.6033 \\
NM & 0.9758 & 0.4582 & 0.0034 & 0.0418 & 0.2050 \\
TX & 0.7629 & 1 & 0.5108 & 0.1285 & 1 \\
\hline
\end{tabular}

Because of the different data dimensions, we use the benefit type cost normalization process to obtain the decision matrix after normalization:

Table 9. The decision matrix after normalization

\begin{tabular}{|c|c|c|c|c|c|}
\hline State 2025 & $\begin{array}{l}\text { Nearly } 20 \text { years of total clean energy } \\
\text { consumption as a percentage of total } \\
\text { energy consumption }\end{array}$ & $\begin{array}{l}\text { The average } \\
\text { price of exported } \\
\text { electricity }\end{array}$ & $\begin{array}{l}\text { The total energy } \\
\text { generated by clean } \\
\text { energy }\end{array}$ & $\begin{array}{l}\text { Regression equation in } \\
\text { each state the coefficient of } \\
\text { pollution energy share }\end{array}$ & $\begin{array}{l}\text { Total output of } \\
\text { coal tar oil in }\end{array}$ \\
\hline $\mathrm{AZ}$ & $83.31 \%$ & 8.764224 & 10335682.734 & 1.785 & 295818.54 \\
\hline $\mathrm{CA}$ & $72.18 \%$ & 10.832016 & 14598811 & 5.486 & 315269.2 \\
\hline NM & $81.30 \%$ & 4.007061 & 49868.796 & 25.491 & 107403.06 \\
\hline TX & $63.56 \%$ & 10.832016 & 7458030.4 & 42.681 & 5225672.9 \\
\hline
\end{tabular}

Because the attribute weights are unknown, we construct a pair comparison matrix to calculate the weight:

$$
\left[\begin{array}{ccccc}
1 & \frac{6}{5} & 1 & \frac{5}{4} & \frac{5}{3} \\
\frac{6}{5} & 1 & \frac{6}{5} & \frac{6}{4} & \frac{6}{3} \\
1 & \frac{5}{6} & 1 & \frac{5}{4} & \frac{5}{3} \\
\frac{4}{5} & \frac{4}{6} & \frac{4}{5} & 1 & \frac{4}{3} \\
\frac{3}{5} & \frac{3}{6} & \frac{3}{5} & \frac{3}{4} & 1
\end{array}\right]
$$

Figure 5. Relevance matrix.
The weights are calculated as follows [0.2318, 0.2561, $0.2134,0.1707,0.1280]$; (The paired comparison matrix program is given in annex 3.).

The calculation formula of weighted arithmetic mean operator is:

$$
W A A_{w}\left(a_{1}, a_{2}, \cdots, a_{n}\right)=\sum_{j=1}^{n} w_{j} a_{j}
$$

Thus, the comprehensive score of the states was calculated: $[\mathrm{AZ}, \mathrm{CA}, \mathrm{NM}, \mathrm{TX}]=[0.7001,0.91825,0.380197,0.69188]$ As you can see from the score, CA is the highest and NM is second. 


\subsection{Strengths and Weaknesses}

We make use of the methods of multiple regression analysis, multi-attribute decision making, principal component analysis to analyze the data for the understanding of the data with more perspectives. We hope to find the difference and commonness of energy consumption in these four states, and then to explain the causes of such from environmental and economic perspectives.

In part $1 \mathrm{D}$, we use the popular GM $(1,1)$ model, however the result is not good and obvious enough.

The evaluating indicators in the multi-attribute decision making can suNMarize the situation of energy consumption in these four states quite well. And we get quite credible decisions based on the five indicators.

We do not have complete and adequate variables of the multiple regression analysis and principal component analysis, and so the results from such analysis may contain some errors. More time and more appropriated influencing factors are to be found if we are to make more accurate analysis.

In the forecasting of part $1 \mathrm{~d}$, because of the large quantity of data, analysis simply with the GM $(1,1)$ model will lead to lowered accuracy rate.

\section{Result}

Through the analysis of SPSS software, we get the multiple regression equation of four states:

$\mathrm{AZ}:-7.272+\mathrm{HYTCB}+1.007 \mathrm{BMTCB}+1.032 \mathrm{SOTXB}+$ 0.096ELEXB + 0.529GETCB-0.006WWTCB

CA:

$3895.0+0.995 \mathrm{HYTCB}+1.029 \mathrm{GETCB}+0.978 \mathrm{BMTCB}+2.691$

SOTXB0.251EMTCB+0.095ARTCB-0.700ELEXB0.122LG

$\mathrm{TCB}+2.566 \mathrm{PLICB}+0.003 \mathrm{NNTCB}$

$\mathrm{NM}: \quad-4269.6+\quad 24.491 \mathrm{ELEXB}+\quad 1.238 \mathrm{BMTCB}+$ $1.566 \mathrm{HYTCB}+3.693 \mathrm{GETCB}+0.056 \mathrm{LGTCB}-0.219 \mathrm{JFTCB}-$

$3.787 \mathrm{SOTXB}+0.014 \mathrm{NNTCB}+0.173 \mathrm{ARTCB}$

TX:

1978.48-5.455EMTCB+6.978BMTCB-6.032WWTCB+64.2

60GETCB-0.047NUETB+1.085HYTCB-17.833SOTXB

In the four states regression equation it can be seen:

The energy use patterns affecting the total energy consumption of renewable energy sources in $A Z$ are mainly [HYTCB, BMTCB, SOTXB, ELEXB, GETCB, WWTCB], of which the coefficients of influence of these methods are not too large; most of them are negative or positive The influence is approximately 1 , in which ELEXB, GETCB showed a small positive correlation and WWTCB showed a small negative correlation.

The energy use patterns of the total renewable energy consumption of CA [HYTCB, GETCB, BMTCB, SOTXB, EMTCB, ARTCB, ELEXB, LGTCB, PLICB and NNTCB], of which SOTXB and PLICB have larger influence coefficients, Of the total amount of renewable energy consumption for the use of clean energy types, from which we can see that CA has greater advantages in the use of clean energy.

There are mainly [ELEXB, BMTCB, HYTCB, GETCB,
LGTCB, JFTCB, SOTXB, NNTCB, ARTCB] which affect the total energy consumption of $\mathrm{NM}$ renewable energy. ELEXB, GETCB and SOTXB have great influence on the entire regression equation, These three ways of using energy are the major contributions of NMs to the total clean energy consumption. And ELEXB coefficient reaches 24.491, NM has a great dependence on ELEXB.

The major energy usage patterns affecting the total energy consumption of TX renewable energy sources are EMTCB, BMTCB, WWTCB, GETCB, NUETB, HYTCB, SOTXB, among which EMEFB, BMTCB, WWTCB, GETCB, NUETB, HYTCB, The coefficients of significant positive correlation were BMTCB and GETCB, of which the GETCB coefficient reached 64.260. The larger four-tert-factor showed significant negative correlations with EMTCB, WWTCB and SOTXB, which could be seen in the renewable energy Contribution, GETCB accounted for a large proportion of TX.

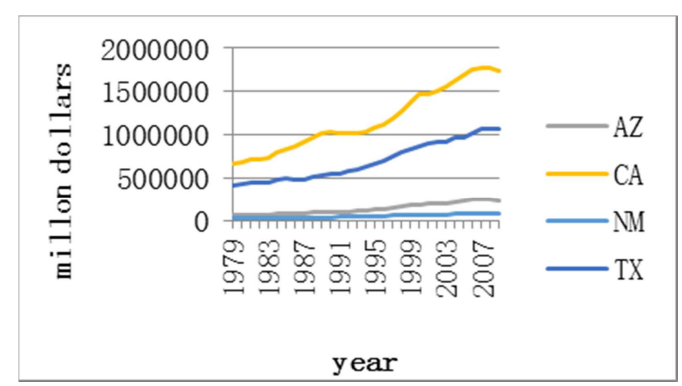

Figure 6. Real gross domestic product.

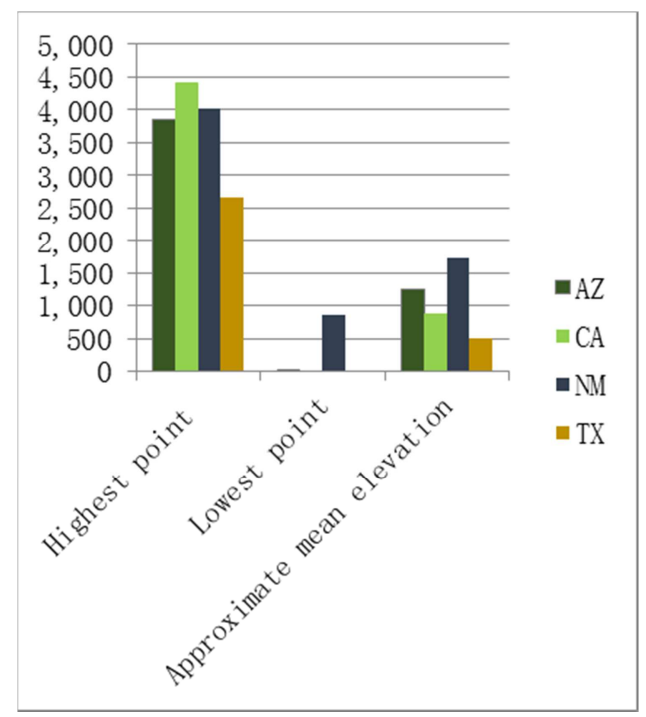

Figure 7. Extreme and mean elevations by state.

Here comes our discussion which is based on above data:

Similarities in Energy Utilization in Four States: It is not difficult to see from the above state energy profiles that hydropower, biomass, geothermal energy, photovoltaics and solar thermal energy are all clean sources of energy utilized by all four states. By further analyzing the efficiency of all clean energy types in each state, we found that hydropower, biomass, and geothermal energy are all energy sources that have good levels of utilization in all four states.

There are different types of energy use in AZ, CA, NM and 
TX. Among them, there are 10 kinds of energy sources available in CA, of which 8 are clean energy sources, and AZ, NM, TX All three states consume considerable amounts of non-clean energy and have mixed positive and negative impacts on their clean energy utilization rates in these three states, all of which have negative utilization rates and can not achieve positive values like the CA. On the other hand, CA's share of total clean energy is the highest percentage of total energy used by states for clean energy. For the use of non-clean energy, NM is the most efficient and efficient use of non-clean energy.

Look from the result of the model, the highest score is CA, from the evaluation standards, the CA total annual consumption of clean energy has a large proportion in total energy consumption, energy production is big, less dependent on non-renewable energy, overall for "coal tar and other typical non-renewable energy dependence is smaller.

Clean energy whose development needs a high economic level, unique natural conditions, and relevant laws and regulations is confronted with many limitations in some places. The CA's GDP index is the first in the four states for almost 20 years and the GDP is far above the second, with the best of the four states. As for the geographical conditions, CA is close to the west of the Pacific Ocean and the whole terrain ups and downs, bordering on the east to the Rocky Mountains terrain with its mountainous terrain, which is very suitable for development of hydropower, wind power and other clean energy. The CA has the largest number of clean energy incentives in four states under the law, which gives the CA the most solid legal basis for the development of clean energy. On science and technology, CA has four states in high-tech industry, the highest rate of science and technology professional, it represents the four states of CA in the science and technology to the highest support for the development of clean energy. Therefore, in the case of the existing situation, the CA with the four states in one of the best prospects to develop clean energy.

It's safe to draw the conclusion that CA makes the best use of clean energy in 2025 and 2050 according to the multi-attribute decision-making model, so its indexes of energy usage will be chosen as the goals of the new energy compact made by four states 。

Table 10. The index of CA's energy usage in 2025 and2050.

\begin{tabular}{|c|c|c|c|c|}
\hline Year & $\begin{array}{l}\text { Nearly } 20 \text { years of total clean energy } \\
\text { consumption as a percentage of total } \\
\text { energy consumption }\end{array}$ & $\begin{array}{l}\text { The average energy } \\
\text { generated by clean energy }\end{array}$ & $\begin{array}{l}\text { The total energy } \\
\text { generated by clean energy }\end{array}$ & $\begin{array}{l}\text { Coal tar energy output } \\
\text { over the past } 20 \text { years the } \\
\text { cumulative combined }\end{array}$ \\
\hline 2025 & $83.2511 \%$ & 6.232011 & 352149.5800 & 385219.32 \\
\hline 2050 & $89.3511 \%$ & 6.832115 & 408498.3800 & 365269.35 \\
\hline
\end{tabular}

\section{Discussion}

Principal component analysis is a multiple statistical analysis method by transforming multiple variables into a few key variables. Principal components are the new indicators compounded from the original indicators. According to the information contained, they are divided into the primary principal components and secondary principal components etc.

Introduction to algorithm:

Let's assume there are $p$ numbers of indicators in our discussion. And we treat them as $\mathrm{p}$ numbers of random variables, and mark them as $\mathrm{x} 1, \mathrm{x} 2, \ldots, \mathrm{xp}$. The principal component analysis is to transform the problem of $\mathrm{p}$ numbers of indicators into a discussion of $p$ numbers of linear combination of indicators, and these new indicators of $\mathrm{fl}$, $\mathrm{f} 2, \ldots, \mathrm{fk}(\mathrm{k} \leq \mathrm{p})$ adequately reflect the information of the original indicators according to the rule of holding basic information, and they are independent of each other.

The process of reducing the discussion of multiple components into only a few compound indicators is called dimensionality reduction in mathematics. The usual practice of principal component analysis is to find the combination $\mathrm{Fi}$ of the original indicators.

Through data analysis, we find 12 ways of energy consumption, namely

[CLTCV KSTCV PCTCV NGTCV ELEXD CLTXB KSTCB BMTCB EMTCB GETCB NNTCB NUETB]

After analyzing the principal components of these data, we got the component matrix of energy consumption, the matrix of the components scoring factors, factor relevance matrix, factor features scree plot etc, and we make use of them to analyze clean energy consumption of these four states (details are listed in appendix 5).

With SPSS, we get the scree plots of the 12 ways of energy consumption:

It's quite obvious that components (CLTXB, KSTCV, PCTCV) are important in these four states, among them CLTXB is significantly important.

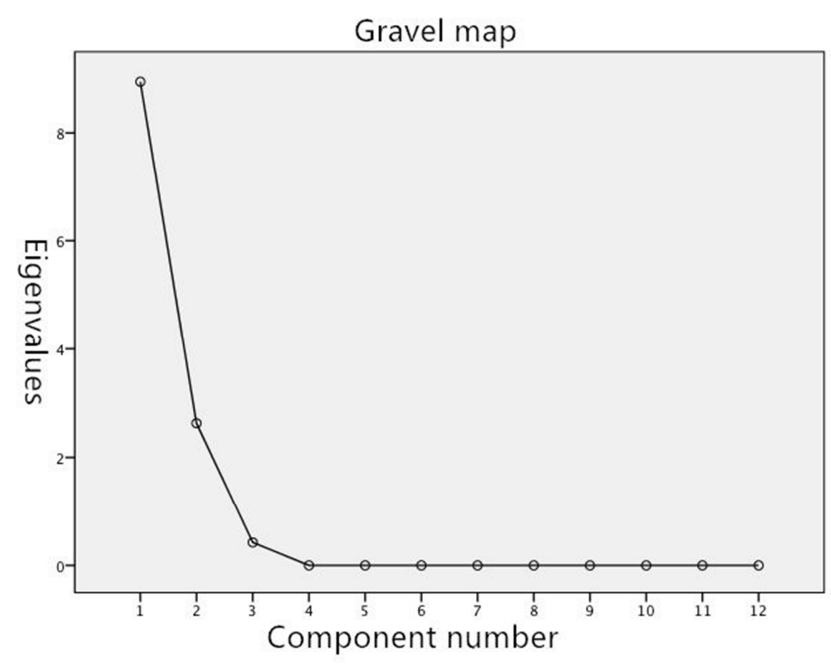

Figure 8. Gravel map. 
To choose the state with the "best" clean energy consumption method through principal component analysis of their energy consumption.

In the above principal component analysis, we also find factor scoring coefficient matrix of the 12 energy consumption ways of the four states, total variance analysis, and find the state with the highest score through the factor scoring coefficient matrix, and choose the state with the highest score as one with the "best" clean energy consumption method.

Table 11. Component scoring coefficient matrix.

\begin{tabular}{|c|c|c|c|c|c|c|c|c|c|c|c|c|}
\hline Ingredient & CLTCV & KSTCV & PCTCV & $\begin{array}{l}\text { NGTC } \\
\text { V }\end{array}$ & $\begin{array}{l}\text { ELEX } \\
\text { D }\end{array}$ & CLTXB & KSTCB & $\begin{array}{l}\text { ВМТС } \\
\text { В }\end{array}$ & $\begin{array}{l}\text { EMTC } \\
\text { B }\end{array}$ & $\begin{array}{l}\text { GETC } \\
\text { B }\end{array}$ & NNTCB & NUETB \\
\hline 1 & 0.042 & 0.105 & 0.09 & 0.111 & 0.111 & 0.107 & 0.11 & 0.101 & 0.096 & 0.067 & 0.103 & 0.091 \\
\hline 2 & 0.352 & 0.122 & 0.219 & 0.036 & 0.013 & 0.105 & 0.035 & 0.161 & 0.192 & 0.305 & 0.142 & 0.066 \\
\hline
\end{tabular}

Table 12. Total variance explained.

\begin{tabular}{lllll}
\hline sum & $\begin{array}{l}\text { Initial eigenvalue Variance } \\
\text { percentage }\end{array}$ & accumulation & sum & $\begin{array}{l}\text { Extract the square sum of loads } \\
\text { Variance percentage }\end{array}$ \\
\hline 8.947 & 74.557 & 74.557 & 8.947 & 74.557 \\
2.630 & 21.913 & 96.471 & 2.630 & 21.913 \\
424 & 3.529 & 100.000 & & \\
$1.577 \mathrm{E}-15$ & $1.315 \mathrm{E}-14$ & 100.000 & & \\
$2.989 \mathrm{E}-16$ & $2.491 \mathrm{E}-15$ & 100.000 & & \\
\hline
\end{tabular}

Primary component scoring coefficient matrix and total variance are used to interpret the 12 indicators and the scores of these four states. The equations are as follows:

$$
\begin{array}{r}
\mathrm{F} 1=0.042 \mathrm{CLTCV}+0.105 \mathrm{KSTCV}+0.090 \mathrm{PCTCV}+0.111 \mathrm{NGTCV}+0.111 \mathrm{ELEXD}+0.107 \mathrm{CLTXB}+0.110 \mathrm{KSTCB} \\
+0.101 \mathrm{BMTCB}+0.096 \mathrm{EMTCB}+0.067 \mathrm{GETCB}+0.103 \mathrm{NNTCB}+0.091 \mathrm{NUETP}
\end{array}
$$

\section{$\mathrm{F} 2=0.352 \mathrm{CLTCV}-0.122 \mathrm{KSTCV}+0.219 \mathrm{PCTCV}+0.036 \mathrm{NGTCV}+0.013 \mathrm{ELEXD}+0.105 \mathrm{CLTXB}-0.035 \mathrm{KSTCB}$ $-0.161 \mathrm{BMTCB}-0.192 \mathrm{EMTCB}-0.305 \mathrm{GETCB}+0.142 \mathrm{NNTCB}+0.066 \mathrm{NUETP}$}

$$
\mathrm{F}=(74.557 / 96.471) \mathrm{F} 1+(21.913 / 96.471) \mathrm{F} 2
$$

the results of the analysis are as follows:

Table 13. The results of the analysis.

\begin{tabular}{lllll}
\hline State & F1 & F2 & F & Rank \\
\hline CA & 522.4739 & 11.459 & 533.9329 & 1 \\
TX & 225.4315 & 23.463 & 278.8945 & 2 \\
NM & 196.2522 & 50.024 & 246.2762 & 3 \\
AZ & 116.0716 & -19.308 & 96.7636 & 4 \\
\hline
\end{tabular}

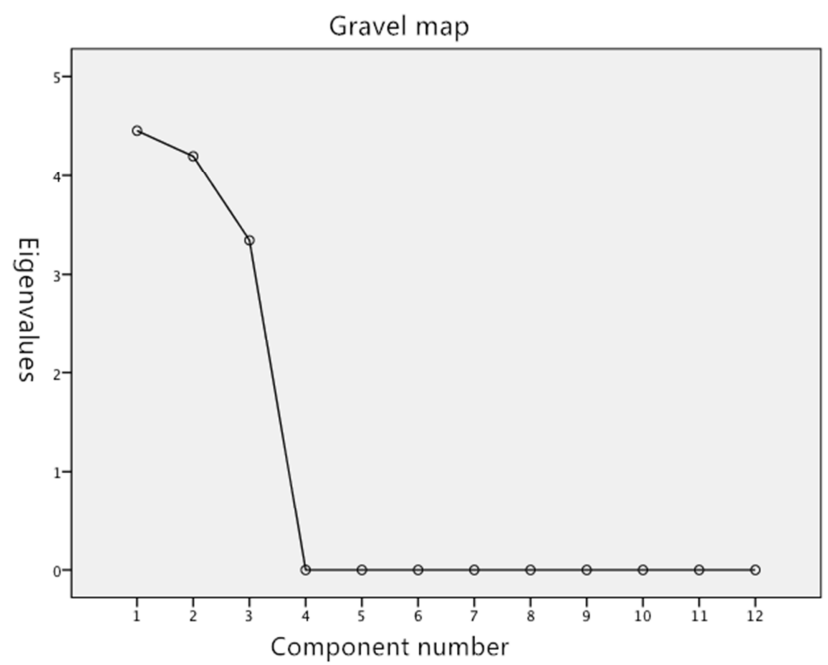

Figure 9. Gravel map in 2025.

TBy using GM $(1,1)$ model, we predict the data of the 12 indicators from 2009 to 2025 and from 2025 to 2050 . And by calculating the sum of 12 indicators from 2009 to 2025 and from 2025 to 2050 respectively, we carry out the principal component analysis, and analyze clean energy consumption of the four states in 2025 and 2050.

In year 2025: Principal component analysis reveals the 2025 components matrix of the 12 indicators in the four states, factor scoring coefficient matrix, factor relevance matrix, and the factor featuring scree plot etc.

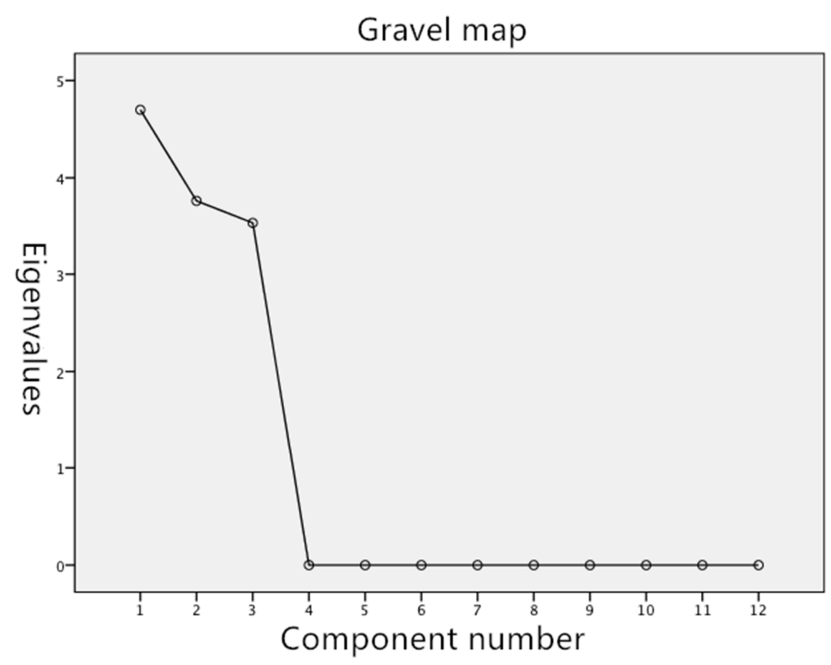

Figure 10. Gravel map in 2050. 
The figures indicate CLTCV, KSTCV, and PCTCV are taking significant roles of clean energy consumption in the four states.

In 2050: Through the prediction the 12 indicators of these four states in 2050, we make principal component analysis with SPSS, and find the scree plot of the time:

We can see that CLTCV, KSTCV, and PCTCV are still taking predominant roles in clean energy consumption, with CLTCV as the most significantly dominant one.

\section{Conclusion}

After the analysis, we find that among the complicated energy consumption methods, CKTXB, KSTCV, and PCTCV are quite significant in the four states.

Through the final calculation, we find that CA and TX have high values, and among the four states, CA plays a leading role in using clean energy in the four states.

\section{Acknowledgements}

It took me nearly two months to finish this paper. I encountered numerous difficulties and obstacles in the process of writing this paper. I spent it with the help of my classmates and teachers. When searching for information in the school library, the teachers of the library have provided me with support and help in many aspects, especially thanks to my thesis instructor, Mr. Li. Without him to help me revise and improve the paper over and over again, there would be no final completion of my thesis. Here, I would like to express my heartfelt thanks to the teachers who have guided and helped me.

At the same time, I would also like to thank the scholars' monographs cited in this paper. Without the enlightenment and help of these scholars' research results, I would not be able to complete the final writing of this paper. At this point, I also want to thank my classmates Yue. $\mathrm{Wu}$, who have given me a lot of useful materials in the process of my thesis writing, and also provide enthusiastic help in the process of paper typesetting and writing.

\section{References}

[1] Y. Sue, S. Y. To, and M. Goto, "The intermediate approach to sustainability enhancement and scale related measures in environmental assessment," EUROPEAN JOURNAL OF OPERATIONALRESEARCH, American, vol. 276, 2019, pp. 744-756.
[2] Y. Gao, Y. Chen, L. Chen, "Experimental investigation on the permeability of a hydrate-bearing reservoir considering over burden pressure". FUEL. American, vol. 246, 2019, pp. 308-318.

[3] C. Ekici, I. Teke, "Global solar radiation estimation from measurements of visibility and air temperature extremes,". ENERGY SOURCES PART ARECOVER YUTI LIZATION AND ENVIRON MENTAL EFFECTS, American, vol. 41, 2019, pp. 1344-1359.

[4] T. P. Miyanawala, R. K. Jaiman, "Decomposition of wake dynamics in fluid-structure interaction via low-dimensional models," JOURNAL OF FLUIDMECHANICS, American, vol. 867, 2019, pp. 723-764.

[5] L. M. Aguiar, J. Polo, J. M. Vindel, "Analysis of satellite derived solar irradiance in islands with site adaptation techniques for improving the uncertainty," RENEWABLEENERGY, American, vol. 135, MAY 2019, pp. 98-107.

[6] X. Xu, C. Chen, "Energy efficiency and energy justice for US low-income households: Ananalysis of multifaceted challenges and potential" ENERGYPOLICY, American, vol. 128, pp. 763-774, MAY 2019.

[7] N. Habibi, I. Howard, S. Simani, "Reliability improvement of wind turbine power generation using model-based fault detection and fault tolerant control: Areview," RENEWABLE ENERGY. American. vol. 135, pp. 877-896, MAY 2019.

[8] X. Han, T. Sun, Q. Feng, "Study on environmental pollution loss measurement model of energy consumption emits and its application in industrial parks," SCIENCE OF THETOTALENVIRONMENT, American, vol. 668, 2019, pp. 1259-1266.

[9] Yuezheng, Gong; Jia, Zhao, "Energy-stable Runge-Kutta schemes for gradient flow models using the energy quadratization approach", APPLIED MATHEMATICS LETTERS vol. 94, 2019, pp. 224-231.

[10] Yu Yan; Qi Li; Weirong Chen, "Optimal Energy Management and Control in Multimode Equivalent Energy Consumption of Fuel Cell/Super capacitor of Hybrid Electric Tram" vol: 66, 2019, pp. 6065-6076.

[11] Xie Yulong; Mendon Vrushali; Halverson, Mark; Assessing overall building energy "performance of a large population of residential single-family homes using limited field data" Vol. 12, 2019, pp. 480-493. 